\title{
A Study on $\mathrm{InGaN} / \mathrm{GaN}$ Multiple Quantum-Well Hydrogen Sensor with HfTiO as Gate Dielectric
}

\author{
Gang Chen, A.H.W. Choi, P.T. Lai
}

\begin{abstract}
A hydrogen sensor based on InGaN/GaN multiple quantum wells (MQWs) was fabricated. A gate dielectric HfTiO was added to stabilize its performance at high temperature. Its hydrogen-sensing properties were studied at high temperatures from $100^{\circ} \mathrm{C}$ to $500^{\circ} \mathrm{C}$. The sensor showed promising hydrogen-sensing properties over a wide temperature range, and could still function beyond $500^{\circ} \mathrm{C}$.
\end{abstract}

\section{INTRODUCTION}

Growing interest in hydrogen as a future energy carrier leads to high interest in hydrogen sensors. Materials with dielectric constant (k) higher than that of $\mathrm{SiO}_{2}$ are called high-k materials. Hf-based films are promising candidates to replace $\mathrm{SiO}_{2}$ as gate dielectric, due to their much higher dielectric constant and stability, besides good electrical performance [1]. Therefore, HfTiO with a relatively high $\mathrm{k}$ of $\sim 50$ is chosen to be the gate dielectric in this hydrogen sensor. The InGaN/GaN MQW structure, where there are localized states of carrier dynamics [2], is widely used in LED and LD devices. In order to see what these localized states can bring to the hydrogen-sensing properties of the sensor, a novel hydrogen sensor based on $\mathrm{InGaN} / \mathrm{GaN}$ MQWs will be fabricated and studied.

\section{EXPERIMENT}

The device with the structure shown in Fig.1 was fabricated. The wafer was cleaned using the conventional RCA method (solution I $\left(\mathrm{H}_{2} \mathrm{O}-\mathrm{H}_{2} \mathrm{O}_{2}-\mathrm{NH}_{4} \mathrm{OH}\right)$ and solution II $\left(\mathrm{H}_{2} \mathrm{O}-\right.$ $\mathrm{H}_{2} \mathrm{O}_{2}-\mathrm{HCl}$ )) followed by a 1-min dipping in $5 \%$ hydrofluoric acid which was used to remove the native oxide. The gate dielectric, 3.6-nm HfTiO, was then deposited at room temperature by RF sputtering of hafnium metal and DC sputtering of titanium metal in a mixed

Gang Chen, A.H.W. Choi and P.T. Lai are with the Department of Electrical and Electronic Engineering, The University of Hong Kong. Email: laip@eee.hku.hk
$\mathrm{Ar} / \mathrm{O}_{2}$ ambient $\left(\mathrm{Ar}\right.$ to $\mathrm{O}_{2}$ ratio $\left.=8: 1\right)$. The electrode, 100-nm Pt with a diameter of 0.5 $\mathrm{mm}$, was then deposited on the gate dielectric by DC sputtering of platinum metal through a stainless-steel shadow mask. The sample then underwent an annealing in a furnace at $650^{\circ} \mathrm{C}$ in $\mathrm{N}_{2}(1000 \mathrm{ml} / \mathrm{min})$ for $10 \mathrm{~min}$.

\begin{tabular}{|c|}
\hline Platinum (Pt) \\
\hline Gate dielectric (HfTiO) \\
\hline Undoped GaV cap $(\sim 25 \mathrm{~nm})$ \\
\hline InGaN/GaN MQWs $(\sim 100 \mathrm{~nm})$ \\
\hline n-GaN (a few $\mu \mathrm{m})$ \\
\hline Silicon \\
\hline
\end{tabular}

Fig.1 structure of the hydrogen sensor

After fabrication of the hydrogen sensor, its hydrogen-sensing properties were studied. Measurements were carried out using a computer-controlled measurement system. A thermostat, a semiconductor parameter analyzer (HP 4145B) and two digital gas flow controllers were connected to a computer and controlled by software programs. The test sample was placed in a stainless-steel closed chamber inside the thermostat, and gases were injected into the chamber through the digital gas flow controllers.

\section{RESULTS AND DISCUSSION}

We can see from Fig.2 that the hydrogen sensor has a high operating temperature of $\sim 450^{\circ} \mathrm{C}$ and the sensor is damaged at $500^{\circ} \mathrm{C}$ as there is too much noise in the I-V curves, likely due to poor electrical contact. However, the device is still sensitive to $\mathrm{H}_{2}$ concentration even at $500^{\circ} \mathrm{C}$. As can be seen, all I-V curves in air or in $\mathrm{H}_{2}$ slightly jitter. In fact, the I-V curves jitter stronger at lower temperatures 
from $100^{\circ} \mathrm{C}$ to $450^{\circ} \mathrm{C}$. In the microstructure of the InGaN/GaN multiple quantum wells, the nano-scale indium composition fluctuations (due to indium aggregation or phase separation) act as quantum dots where carriers are deeply localized and their migration towards dislocations is hindered [3]. Thus the current produced by carriers' migration is not uniform. Therefore, the indium composition fluctuations might account for the slightly-jittering I-V curves of the sensor. Moreover, the localized carriers are activated as the temperature goes up. The localization effect is cancelled by thermal process at sufficiently high temperatures [4], which might result in smoother I-V curves (i.e. I-V curves jitter less) at higher temperatures from $100^{\circ} \mathrm{C}$ to $450^{\circ} \mathrm{C}$.
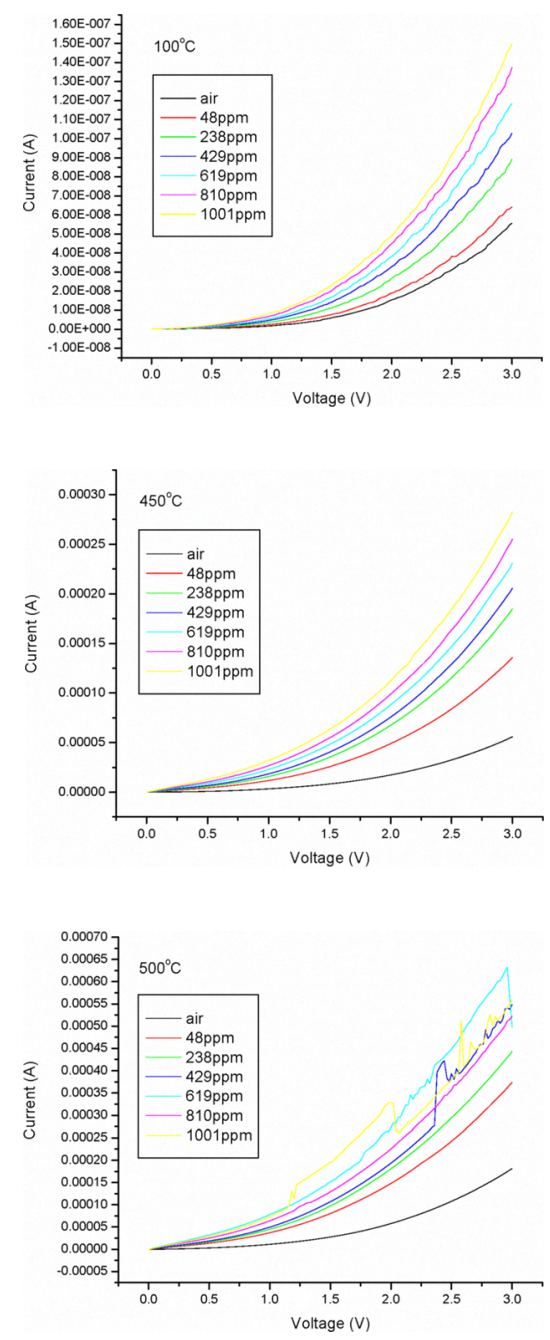

Fig. $2 \mathrm{I}-\mathrm{V}$ curves of the sensor at $100^{\circ} \mathrm{C}, 450^{\circ} \mathrm{C}$, $500^{\circ} \mathrm{C}$

The hydrogen concentration-sensitivity characteristics of the sensor are depicted in Fig.3. The sensitivity is defined as $\left(\mathrm{I}_{\mathrm{H} 2}-\mathrm{I}_{\text {air }}\right) /$ $I_{\text {air }}$, where $I_{H 2}$ and $I_{\text {air }}$ are measured in hydrogen and air respectively. As can be seen, the sensitivity increases when the hydrogen concentration increases at each temperature except $500^{\circ} \mathrm{C}$. This is due to an increase of the current in hydrogen-containing ambient caused by the lowering of the Schottky barrier at the $\mathrm{Pt} / \mathrm{HfTiO}$ interface. The hydrogen-sensing mechanism is interpreted as follows $[5,6]$. First, hydrogen molecules are dissociated to hydrogen atoms by the catalytic Pt metal. Then, hydrogen atoms diffuse toward the $\mathrm{Pt} / \mathrm{HfTiO}$ interface. The accumulated hydrogen atoms form a dipolar layer to build a local electric field, and thus lower the Schottky barrier height.

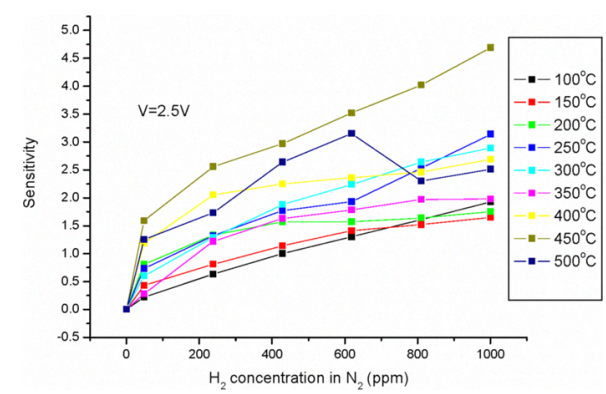

Fig.3 hydrogen concentration-sensitivity characteristics of the sensor

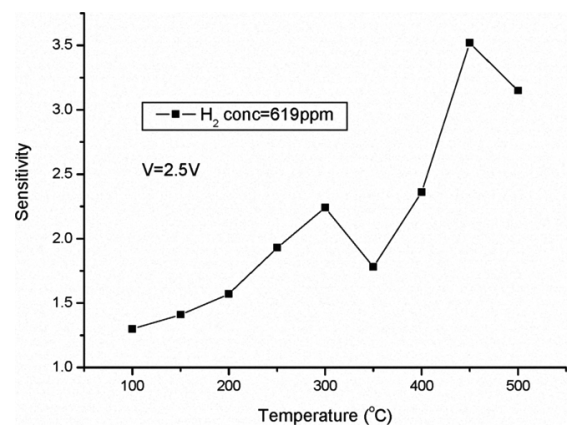

Fig.4 temperature-sensitivity characteristics of the sensor

Fig.4 depicts the temperature-sensitivity characteristics of the sensor. The sensitivity increases with the temperature up to $300^{\circ} \mathrm{C}$, then it decreases from $300^{\circ} \mathrm{C}$ to $350^{\circ} \mathrm{C}$. However, the sensitivity later achieves its maximum at $450^{\circ} \mathrm{C}$. This phenomenon can be explained as follows. When the temperature increases, the hydrogen under higher pressure will bombard the surface of the Pt electrode more frequently. Hence, more hydrogen molecules can adsorb at the surface of the $\mathrm{Pt}$ electrode and also decompose faster into hydrogen atoms, giving higher sensitivity [7]. Nevertheless, further increasing the operating temperature $\left(300^{\circ} \mathrm{C}-350^{\circ} \mathrm{C}\right)$, more and more trapped electronic defects in the gate dielectric 
or V defects in MQWs are thermally-activated and contribute to the conduction in the device. As an overall result, the contribution of the thermally-activated trapped electronic defects is dominant $\left(\mathrm{I}_{\text {air }}\right.$ increases more than $\left.\mathrm{I}_{\mathrm{H} 2}\right)$ and thus the sensitivity decreases [8]. Yet, when the operating temperature further increases $\left(350^{\circ} \mathrm{C}-450^{\circ} \mathrm{C}\right)$, the contribution of the dissociation of $\mathrm{H}_{2}$ into $\mathrm{H}$ atoms is dominant $\left(\mathrm{I}_{\mathrm{H} 2}\right.$ increases more than $\left.\mathrm{I}_{\mathrm{air}}\right)$ and hence the sensitivity rises again.

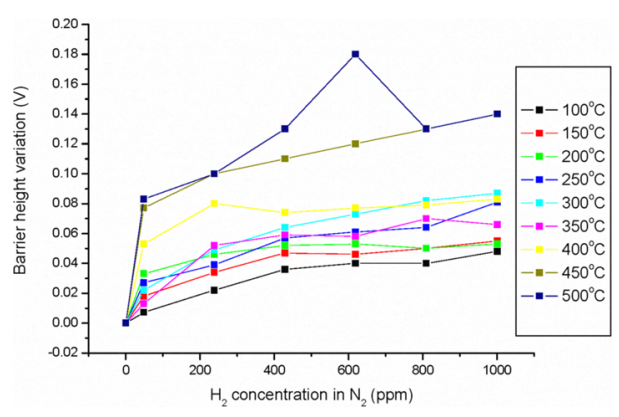

Fig.5 hydrogen concentration-barrier height variation characteristics of the sensor

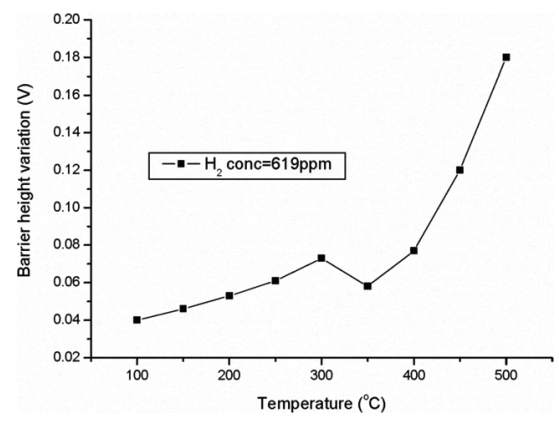

Fig.6 temperature-barrier height variation characteristics of the sensor

The Schottky barrier height $\left(\Phi_{\mathrm{b}}\right)$ can be calculated as: $\Phi_{b}=(k T / q) \ln \left(A A^{* *} T^{2} / I_{0}\right)$, where $\mathrm{k}$ is the Boltzmann constant; $\mathrm{T}$ is the absolute temperature; $A$ is the Schottky contact area; $\mathrm{A}^{* *}$ is the effective Richardson constant; and $\mathrm{I}_{0}$ is the saturation current. The Schottky barrier height variation $\left(\Delta \Phi_{b}\right)$ is defined as: $\Delta \Phi_{b}=$ $\Phi_{\mathrm{b}}$ (air) - $\Phi_{\mathrm{b}}\left(\mathrm{H}_{2}\right)$, where $\Phi_{\mathrm{b}}$ (air) is the Schottky barrier height in an air atmosphere, and $\Phi_{b}\left(\mathrm{H}_{2}\right)$ is the Schottky barrier height in a hydrogen-containing ambient. $\mathrm{I}_{\mathrm{o}}$ (in air or in $\mathrm{H}_{2}$ ) can be found from the corresponding $y$ intercept of the graph of $\ln (\mathrm{I})$ versus $\mathrm{V}$, and then $\Phi_{b}$ can be calculated using the equation above. As a result, $\Delta \Phi_{\mathrm{b}}$ will be known.

The hydrogen concentration-barrier height variation $\left(\mathrm{H}_{2}\right.$ conc $\left.-\Delta \Phi_{\mathrm{b}}\right)$ characteristics are described in Fig.5. In general, $\Delta \Phi_{b}$ has an upward trend at each temperature except $500^{\circ} \mathrm{C}$ due to damaged device. As mentioned earlier, the Schottky barrier height is lowered in the hydrogen-containing ambient. Therefore, $\Delta \Phi_{\mathrm{b}}$ defined as $\Phi_{\mathrm{b}}($ air $)-\Phi_{\mathrm{b}}\left(\mathrm{H}_{2}\right)$ rises as the $\mathrm{H}_{2}$ concentration increases.

The temperature- $\Delta \Phi_{\mathrm{b}}$ characteristics (Fig.6) of the sensor are similar to the temperaturesensitivity characteristics (Fig.4) below $450^{\circ} \mathrm{C}$. They share the same explanations as indicated above.

\section{CONCLUSION}

The InGaN/GaN MQW hydrogen sensor with HfTiO gate dielectric has good performance at high temperatures, and the device is still sensitive to $\mathrm{H}_{2}$ even at $500^{\circ} \mathrm{C}$. The carrier-localization effect in the MQWs has an impact on the shape of its I-V curves, especially at lower temperatures. However, the sensor shows promising hydrogen-sensing properties over a wide high temperature range from $100^{\circ} \mathrm{C}$ to $450^{\circ} \mathrm{C}$, and could still function beyond $500^{\circ} \mathrm{C}$.

\section{ACKNOWLEGEMENT}

This work is financially supported by the Research Grants Council (RGC) of Hong Kong Special Administrative Region (HKSAR), China, under Project CRF (HKUST 2/07C) (Project No. CA07/08.EG02), and the University Development Fund (Nanotechnology Research Institute, 00600009) of The University of Hong Kong.

\section{REFERENCES}

[1] K.P. Bastos, C. Driemeier, R.P. Pezzi, G.V. Soares, L. Miotti, J. Morais, I.J.R. Baumvol, R.M. Wallace, "Thermal stability of Hf-based high-k dielectric films on silicon for advanced CMOS devices," Materials Science and Engineering B, vol.112, p.134-138, 2004

[2] S.W. Feng, Y.C. Cheng, Y.Y. Chung, M.H. Mao, C.C. Yang, Y.S. Lin, K.J. Ma, J.I. Chyi, "Carrier dynamics in InGaN/GaN multiple quantum well structures," Proceedings of SPIE, vol.4594, p.197-200, 2001

[3] Y.S. Lin, C. Hsu, K.J. Ma, S.W. Feng, Y.C. Cheng, Y.Y. Chung, C.W. Liu, C.C. Yang, J.I. Chyi, "Microstructure Studies of InGaN/GaN Multiple Quantum Wells," CLEO, vol.2, p.218-219, 2001 
[4] J.C. Lee, Y.F. Wu, Y.P. Wang, T.E. Nee, "Temperature and current dependences of electroluminescence from InGaN/GaN multiple quantum wells," Journal of Crystal Growth, vol.310, p.5143-5146, 2008

[5] C.W. Hung, H.L. Lin, H.I. Chen, Y.Y. Tsai, P.H. Lai, S.I. Fu, W.C. Liu, "A Novel $\mathrm{Pt} / \mathrm{In}_{0.52} \mathrm{Al}_{0.48}$ As Schottky Diode-Type Hydrogen Sensor," IEEE Electron Device Letters, vol.27, p.951-954, 2006

[6] T.H. Chou, Y.K. Fang, Y.T. Chiang, K.C. Lin, C.I. Lin, C.H. Kao, H.Y. Lin, "The $\mathrm{Pd} / \mathrm{TiO}_{2} / \mathrm{n}$-LTPS Thin-Film Schottky Diode on
Glass Substrate for Hydrogen Sensing Applications," IEEE Electron Device Letters, vol.29, p.1232-1235, 2008

[7] W.M. Tang, "MISiC Schottky-Diode Hydrogen Sensors with Different Gate Insulators," $\mathrm{PhD}$ thesis at The University of Hong Kong, p.61-64, 2008

[8] X.F. Chen, W.G. Zhu, O.K. Tan, "Microstructure, dielectric properties and hydrogen gas sensitivity of sputtered amorphous $\mathrm{Ba}_{0.67} \mathrm{Sr}_{0.33} \mathrm{TiO}_{3}$ thin films," Materials Science and Engineering B, vol.77, p.177-184, 2000 